\title{
Predicting 15 year chronic bronchitis mortality in the Whitehall Study
}

\author{
KRISTIE L EBI-KRYSTON \\ From the Department of Epidemiology, London School of Hygiene and Tropical Medicine, Keppel Street, London \\ WCIE 7HT.
}

ABSTRACT Fifteen year chronic bronchitis mortality was investigated among 17717 male civil servants aged 40-64 years participating in the Whitehall Study. Associations were assessed between mortality and Medical Research Council standardised questions about chronic phlegm production and breathlessness, and a measure of lung function. Low FEV 1 was the most powerful single predictor of mortality; controlling for age, smoking habits and employment grade, the relative hazards ratio (RHR) was 20 . Using mortality rates standardised for age and smoking, the proportion of mortality in the total population statistically attributable to low $\mathrm{FEV}_{1}$ (population excess fraction) was $\mathbf{5 7 \%}$. Breathlessness while walking on the level was the best predictor among the questions and combinations of questions; the relative hazards ratio was 12 and the population excess fraction, $39 \%$. A Medical Research Council definition of chronic bronchitis including chronic phlegm production and breathlessness was also strongly associated with chronic bronchitis mortality $(\mathrm{RHR}=13)$; however, the population excess fraction was only $20 \%$. This definition identified only $30 \%$ of the 64 deaths, and added almost nothing to prediction by $\mathrm{FEV}_{1}$ alone. The results suggest that although the combination of chronic phlegm production and chronic airflow limitation is strongly associated with mortality from chronic bronchitis, the presence of chronic phlegm production alone is not associated with mortality.

One of the definitions of chronic bronchitis recommended by the Bronchitis Research Committee of the Medical Research Council in $1965^{12}$ includes report of both chronic phlegm production and breathlessness, where breathlessness was used as an indication of chronic airflow obstruction. This definition was based on the belief that individuals reporting chronic phlegm production would later become disabled by chronic airflow obstruction. ${ }^{3}$ Other definitions of chronic bronchitis have been proposed, including chronic phlegm production alone, and cough with expectoration not attributable to other lung diseases. ${ }^{14}$ Recent studies have shown that chronic phlegm production and chronic airflow obstruction are two separate disease processes. ${ }^{5-10}$ Fletcher and Pride ${ }^{11}$ recently advocated that the term chronic bronchitis be used "only to denote chronic or recurrent bronchial hypersecretion."

While the design of future epidemiological investigations can benefit from current knowledge, analyses of data already collected must be limited to the questions asked and the measurements taken. Such analyses have provided, and continue to provide, valuable insights into the determinants of chronic diseases. Many studies have used the Medical Research Council (MRC) questions about chronic phlegm production and breathlessness walking on the level, or other questions derived from or comparable to them. This study was designed to compare those standardized questions, a standard lung function measurement, and combinations of questions and measurement, to determine which provides the most satisfactory prediction of 15 year mortality from chronic bronchitis in the Whitehall Study of male civil servants.

\section{Methods}

In $1967-69,18403$ male civil servants aged 40-64 years were examined and questioned in the Whitehall Study. ${ }^{12}$ In the present analysis, smokers of only pipes or cigars $(n=640)$ and men with unknown smoking habits $(n=46)$ were excluded, leaving a total population of 17717 . Death certificates were provided for each subject who died within the United Kingdom by the Central Registry of the National Health Service. Underlying causes of death were coded to the 8th revision of the International Classification of 
Diseases. There were 64 deaths from chronic bronchitis (ICD8 491.0-491.9) in the 15 years of follow up. Analyses were repeated for the 76 deaths from chronic airways obstruction (ICD8 490.0-492.9) and the results were similar (not shown).

The four questions in the shorter MRC bronchitis questionnaire $^{12}$ were analysed individually and in combination. These questions were formulated by a subcommittee of the Medical Research Council's Committee on the Aetiology of Chronic Bronchitis, ${ }^{13}$ and were based on questions which had been shown to be reliable and valid in diagnosing chronic bronchitis. ${ }^{14}$ The questions about phlegm most mornings for 3 months (persistent morning phlegm or simple bronchitis) and about a recent period of increased cough and phlegm were asked only of men who responded affirmatively to the question about regular phlegm in the winter. "Persistent and increased phlegm" includes both persistent phlegm and a recent period of increased cough and phlegm lasting 3 weeks or more. This definition does not consider the responses to the question about breathlessness walking on the level. "Persistent and increased phlegm and breathlessness" is an MRC definition of chronic bronchitis.

Pulmonary function was assessed by spirometry. Three blows were recorded, and the mean forced expiratory volume in one second $\left(\mathrm{FEV}_{1}\right)$ was obtained from the two blows with the highest forced vital capacity (FVC). Predicted values of $\mathrm{FEV}_{1}$ were obtained from a linear regression of age and height for men responding negatively to the MRC questions about winter phlegm and breathlessness, and to questions about wheeze and weather affecting breathing $(n=2806)$. Percent of predicted $F^{2} V_{1}$ was calculated, and values below $65 \%$ ("low FEV 1 ") were used as a measure of pulmonary impairment. " $\mathrm{FEV}_{1}$ $<65 \%$ predicted, without persistent phlegm" includes only men with low FEV 1 who did not report persistent phlegm production. The results for the 2353 men with persistent phlegm without $\mathrm{FEV}_{1}$ are similar to those for men with "persistent and increased phlegm without breathlessness" and so are not reported.

Cox proportional hazards regression models were developed using BMDP- $2 \mathrm{~L}^{15}$ for the various measures of respiratory impairment, controlling for potential confounding by age, smoking habits and employment grade. Mean ages were slightly higher and proportions currently smoking or with high employment grade were slightly lower for men with breathlessness, "persistent and increased phlegm and breathlessness," low FEV , or any combination of these measures (not shown). Age was entered as single years; smoking habits as never smoker, ex-smoker, or smoker, and number of cigarettes smoked daily; and employment grade was entered as low (clerical or other) or high (administrative, executive, or professional, scientific and technical). The magnitudes of associations, adjusting for covariates, were estimated by calculating relative hazards ratios from the regression coefficients.

Population excess rates and population excess fractions ${ }^{16}$ were calculated using mortality rates standardised for age and smoking.

\section{Results}

Prevalence rates of the various measures of respiratory impairment ranged from a high of $23 \cdot 1 \%$ for "usually have phelgm in winter" to a low of $0.9 \%$ for "low $\mathrm{FEV}_{1}$ and persistent and increased phlegm and breathlessness" (table 1). Approximately half of the men who reported breathlessness or had a low FEV 1 also reported persistent phelgm production. The numbers of deaths attributed to chronic bronchitis were small. None of the measures identified all 64 deaths; the majority of deaths were identified by the presence of low FEV 1 alone $(n=45)$ or by low FEV plus breathlessness $(n=50)$. Adding "persistent and increased phlegm and breathlessness" identified only one additional death to those identified by low FEV . $^{\text {. }}$ Smoking was a major risk factor for chronic bronchitis mortality. Only one death occurred among never smokers; there were 14 deaths $(21.9 \%)$ among exsmokers and $49(76 \cdot 6 \%)$ among smokers.

All of the measures except "persistent phlegm without breathlessness" were significantly associated with chronic bronchitis mortality in Cox proportional hazards regression models (table 1 ). The relative hazards ratios were highest for low $\mathrm{FEV}_{1}$ alone or in combination with breathlessness or "persistent and increased phlegm and breathlessness" (RHR = 19-26). The ratios were lower, but still large $(\mathrm{RHR}=12)$ for "breathlessness walking on the level" and "persistent and increased phlegm and breathlessness." Excluding men who also reported persistent phlegm production markedly reduced the relative hazards ratios for breathlessness (11.7 to 3.4$)$ and low $\mathrm{FEV}_{1}$ (19.9 to 4.4), which suggests that the presence of both persistent phlegm production and airflow limitation predict higher mortality from chronic bronchitis. However, persistent phlegm production without breathlessness or low $\mathrm{FEV}_{1}$ was not significantly associated with mortality.

Of men reporting breathlessness, $319(32.6 \%)$ also had low $\mathrm{FEV}_{1}$; and $153(52.6 \%)$ of men with "persistent and increased phlegm and breathlessness" also had low $\mathrm{FEV}_{1}$. Further Cox proportional hazards regression models were developed to assess the associations of breathlessness and "persistent and increased phlegm and breathlessness" with mortality rates while controlling for $\mathrm{FEV}_{1}$ percent predicted (not shown). The relative hazards ratios were 
Table 1 Prevalence rates and estimated parameters of Cox proportional hazards regression models for 15 year chronic bronchitis mortality by various measures of respiratory impairment, males 40-64 years, Whitehall Study

\begin{tabular}{lrrr}
\hline (a) Model & Coefficient & $S E$ & $R H R$ \\
\hline Age (single years) & 0.1572 & 0.0260 \\
Smoking habits & 1.7167 & 1.17 \\
Ex-smoker $v$ non-smoker & 2.1055 & 1.0355 \\
Smoker $v$ non-smoker & 0.0352 & 0.0120 \\
Number of cigarettes smoked daily & 1.2727 & 0.2750 & 8.21 \\
Employment grade (low $v$ high) & 1.04
\end{tabular}

(b) Measures of respiratory impairment (added individually to model above)

\begin{tabular}{|c|c|c|c|c|c|}
\hline & $\begin{array}{l}\text { Prevalence } \\
(\%)\end{array}$ & Coefficient & $S E$ & $R H R^{*}$ & Deaths \\
\hline Usually have phlegm in winter & 23.1 & $1 \cdot 3807$ & 0.2792 & 3.98 & 44 \\
\hline Persistent morning phlegm & $15 \cdot 8$ & 1.3700 & $0 \cdot 2628$ & 3.94 & 37 \\
\hline Recent period of increased cough and phlegm & $9 \cdot 7$ & 0.6794 & 0.1305 & 1.97 & 27 \\
\hline Persistent and increased phlegm & $7 \cdot 2$ & 1.4213 & 0.2664 & $4 \cdot 14$ & 24 \\
\hline Breathless walking on the level & $5 \cdot 5$ & 2.4594 & 0.2586 & $11 \cdot 70$ & 33 \\
\hline Persistent phlegm without breathlessness & $13 \cdot 6$ & -0.2508 & 0.3262 & 0.78 & 12 \\
\hline Breathless without persistent phlegm & $3 \cdot 3$ & $1 \cdot 2082$ & 0.3795 & 3.35 & 8 \\
\hline Persistent and increased phlegm and breathless & $1 \cdot 7$ & $2 \cdot 5216$ & 0.2891 & $12 \cdot 45$ & 19 \\
\hline FEV $1<65 \%$ predicted & $6 \cdot 4$ & $2 \cdot 9883$ & 0.2839 & $19 \cdot 85$ & 45 \\
\hline FEV $1<65 \%$ predicted without persistent phlegm & 3.9 & 1.4691 & 0.3058 & $4 \cdot 35$ & 14 \\
\hline FEV $1<65 \%$ predicted or breathless & $10 \cdot 2$ & 2.9665 & 0.3111 & $19 \cdot 42$ & 50 \\
\hline FEV $1<65 \%$ predicted and breathless & 1.8 & $3 \cdot 1737$ & $0 \cdot 2659$ & 23.90 & 28 \\
\hline FEV $1<65 \%$ predicted or phlegm and breathlesst & $7 \cdot 2$ & $3 \cdot 2873$ & $0 \cdot 2833$ & $26 \cdot 77$ & 46 \\
\hline FEV $1<65 \%$ predicted and phlegm and breathless & 0.9 & 2.9726 & 0.2975 & $19 \cdot 54$ & 17 \\
\hline
\end{tabular}

* Relative hazards ratio

t Adjusted for age only

markedly reduced, to $2 \cdot 89$ for breathlessness and to 2.25 for "persistent and increased phlegm and breathlessness." Although airflow limitation confounded the associations between these measures and mortality, breathlessness and "persistent and increased phlegm and breathlessness" remained significantly associated with mortality.

Using chronic bronchitis mortality rates standardised for age and smoking, the population excess rates per 1000 were calculated (mortality rates in the total population statistically attributed to the measure) together with the population excess fractions (proportion of mortality in the total population statistically attributable to the measure) for selected measures of respiratory impairment. These results are shown in table 2. Both statistical measures were highest for low $\mathrm{FEV}_{1}$ and low $\mathrm{FEV}_{1}$ plus either breathlessness or "persistent and increased phlegm and breathlessness" (population excess rates $=1.6-1.8$ per 1000 , population excess fractions $=57-67 \%$ ). Persistent phlegm and breathlessness had intermediate values of population excess rates $(1 \cdot 1-1 \cdot 2$ per 1000$)$ and population excess fractions (34-39\%), with the other measures having smaller values.

As shown in the figure, the distribution of values of $\mathrm{FEV}_{1}$ (percent of predicted) for men who died of chronic bronchitis was much lower than the distribution for men who did not. Using a cut off of less than $65 \%$ predicted captures most of the deaths without including too many false positives. The distributions of values were similar for smokers and $\vec{c}$ ex-smokers; $70 \%$ of the deaths (34 of 49 smokers and 10 of 14 ex-smokers) occurred in men with a low FEV

\section{Discussion}

These analyses of a group of male civil servants suggest that low $F E V_{1}$ is the best single predictor of 15 year mortality from chronic bronchitis; the $6.4 \%$ of

Table 2 Population excess rates and population excess fractions for 15 year chronic bronchitis mortality by various measures of respiratory impairment, males 40-64 years, Whitehall Study*

\begin{tabular}{|c|c|c|}
\hline Measures of respiratory impairment & $\begin{array}{l}\text { Population } \\
\text { Excess rate } \\
\text { (per 1000) }\end{array}$ & $\begin{array}{l}\text { Population } \\
\text { Excess fraction } \\
(\%)\end{array}$ \\
\hline Persistent morning phlegm & 1.09 & $34 \cdot 2$ \\
\hline Persistent and increased phlegm & 0.78 & $23 \cdot 8$ \\
\hline Breathless walking on the level & $1 \cdot 20$ & $38 \cdot 6$ \\
\hline $\begin{array}{l}\text { Persistent and increased phlegm } \\
\text { and breathless }\end{array}$ & 0.64 & 19.8 \\
\hline FEV $_{1}<65 \%$ predicted & 1.57 & $56 \cdot 7$ \\
\hline $\begin{array}{l}\text { FEV }_{1}<65 \% \text { predicted or } \\
\text { breathless }\end{array}$ & 1.83 & $67 \cdot 1$ \\
\hline $\begin{array}{l}\text { FEV } 1<65 \% \text { predicted and } \\
\text { breathless }\end{array}$ & 0.91 & $30 \cdot 1$ \\
\hline $\begin{array}{l}\text { FEV } 1<65 \% \text { predicted or phlegm } \\
\text { and breathless }\end{array}$ & 1.62 & 59.6 \\
\hline $\begin{array}{l}\text { FEV } 1<65 \% \text { predicted and phlegm } \\
\text { and breathless }\end{array}$ & 0.53 & 16.6 \\
\hline
\end{tabular}

* Based on mortality rates adjusted for age and smoking 


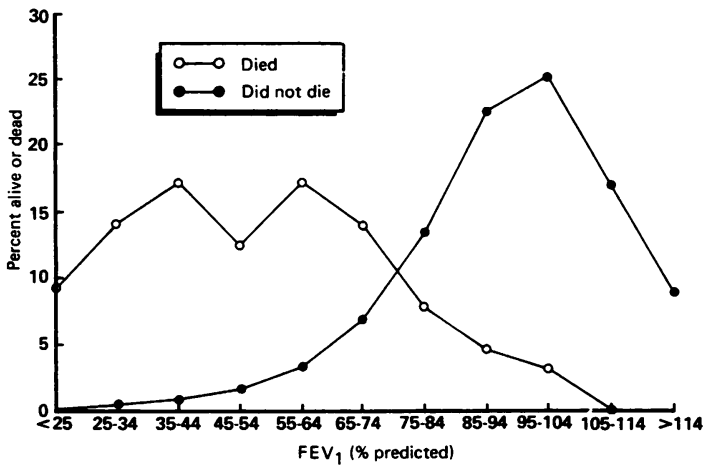

Figure Distribution of values of FEV 1 per cent of predicted for men who died from chronic bronchitis and men who did not, Whitehall Study

men in the study with low $\mathrm{FEV}_{1}$ experienced $70 \%$ of the chronic bronchitis deaths. This is reflected in the high relative hazards ratio (20), population excess rate (1.6 per 1000$)$, population excess fraction $(57 \%)$, and the distribution of values of $\mathrm{FEV}_{1}$ (percent of predicted) for men who died and those who did not. Adding men with breathlessness slightly increased the number of deaths identified (to 50), the population excess rate (to 1.8 per 1000 ) and the population excess fraction (to $67 \%$ ), while increasing the size of the subgroup by $37 \%$, resulting in a lower subgroup specific mortality rate. Adding men with "persistent and increased phlegm and breathlessness" had little effect on prediction. The population excess rates and fractions were smaller for combinations of both low $\mathrm{FEV}_{1}$ and either breathlessness or "persistent and increased phlegm and breathlessness" as were the number of deaths identified, making these combinations less useful predictors.

Relative hazards ratios were large (12) for both "persistent and increased phlegm and breathlessness" and breathlessness. The population excess rate and excess fraction was higher for breathlessness than for "persistent and increased phlegm and breathlessness," which suggests that breathlessness may be the better predictor of chronic bronchitis mortality. Relatively few deaths occurred among men with "persistent and increased phlegm and breathlessness" (19 of 64). The remaining measures of respiratory impairment had much smaller relative hazards ratios with chronic bronchitis mortality. Persistent morning phlegm identified approximately the same number of deaths as breathlessness, and the population excess rates and fractions were similar. However, the prevalence rate was about three times that of breathlessness, which suggests that breathlessness is a more specific predictor of mortality.
The relatively poor ability of one MRC definition of chronic bronchitis to predict mortality from chronic bronchitis is interesting. Including in the definition both chronic phlegm production, which was not lethal in this study, and breathlessness, which was, may have weakened its predictive ability. Nearly all of the deaths from chronic bronchitis occurred among smokers. Mortality rates from chronic bronchitis have been decreasing, ${ }^{17}$ which may in part be due to lower rates of cigarette smoking and to changes in cigarettes, specifically lower average tar yields. ${ }^{18}$ Lower tar cigarettes may not have the same influence on chronic phlegm production and airflow obstruction, ${ }^{19}$ further diminishing the predictive ability of the definition.

In summary, these analyses suggest that a measure of reduced lung function provides the best prediction in these data of subsequent mortality from chronic bronchitis. If lung function measurements are not available, the next best choice is the question about breathlessness walking on the level. "Persistent and increased phlegm and breathlessness" predicts mortality through its association with airways obstruction.

The author gratefully acknowledges the helpful suggestions of Professor G Rose.

The study was supported in part by Training Grant No 5 T32 HLO7337-09 from the National Heart, Lung and Blood Institute.

Address for correspondence and reprints: Dr Kristie $L$ Ebi-Kryston, Department of Environmental and Preventive Medicine, The Medical College of St Bartholomew's Hospital, Charterhouse Square, London ECIM 6BQ.

\section{References}

${ }^{1}$ Medical Research Council. Definition and classification of chronic bronchitis for clinical and epidemiological purposes. Lancet 1965; i: 775-9.

2 Medical Research Council. Questionnaire on respiratory symptoms and instructions for its use. London: Medical Research Council, 1966.

${ }^{3}$ Fletcher CM. Terminology in chronic obstructive lung diseases. J Epidemiol Community Health 1978; 32: 282-8.

${ }^{4}$ Ciba Foundation Guest Symposium. Terminology, definitions and classifications of chronic pulmonary emphysema and related conditions. Thorax 1959; 14: 286-99.

${ }^{5}$ Higgins MW, Keller JB. Predictors of mortality in the adult population of Tecumseh. Respiratory symptoms, chronic respiratory disease, and ventilatory lung function. Arch Environ Health 1970; 21: 418-24.

${ }^{6}$ Fletcher CM, Peto R, Tinker CM, Speizer FE: The natural history of chronic bronchitis and emphysema. Oxford: Oxford University Press, 1976.

${ }^{7}$ Fletcher CM, Peto R. The natural history of chronic airflow obstruction. Br Med J 1977; i: 1645-8. 
${ }^{8}$ Kauffmann F, Drouet D, Lellouch J, Brille D. Twelve years' spirometric changes among Paris area workers. Int J Epidemiol 1979; 8: 201-12.

${ }^{9}$ Peto R, Speizer FE, Cochrane AL, et al. The relevance in adults of air-flow obstruction, but not of mucus hypersecretion, to mortality from chronic lung disease. Results from 20 years of prospective observation. Am Rev Respir Dis 1983; 128: 491-500.

${ }^{10}$ Ebi-Kryston KL. Respiratory symptoms and measurements as predictors of 10-year mortality from respiratory disease, cardiovascular disease, and all causes in the Whitehall study. J Clin Epidemiol 1988; 41: 251-60.

${ }^{11}$ Fletcher CM, Pride NB. Definitions of emphysema, chronic bronchitis, asthma, and airflow obstruction: 25 years on from the Ciba symposium. Thorax 1984; 39: 81-85.

12 Reid DD, Brett GZ, Hamilton PJS, Jarrett RJ, Keen H, Rose G. Cardiorespiratory disease and diabetes among middle-aged male civil servants. A study of screening and intervention. Lancet 1974; i: 469-73.
${ }^{13}$ Medical Research Council, Committee on the Aetiology of Chronic Bronchitis. Standardized questionnaires on respiratory symptoms. $\mathrm{Br} \mathrm{Med} J \mathrm{1960}$; ii: 1665.

14 Cochrane AL, Chapman PJ, Oldham PD. Observers' errors in taking medical histories. Lancet 1951; i: 1007-9.

${ }^{15}$ Dixon WJ, ed. BMDP statistical software, 1983 printing with additions. Berkeley: University of California Press, 1983.

${ }^{16}$ Last JM, ed. A dictionary of epidemiology. Oxford: Oxford University Press, 1983.

${ }^{17}$ Melia RJW, Swan AV. International trends in mortality rates for bronchitis, emphysema and asthma during the period 1971-1980. World Health Stat $Q$ 1986; 39: 206-17.

${ }^{18}$ Capell PJ. Trends in cigarette smoking in the United Kingdom. Health Trends 1978; 10: 49-54.

${ }^{19}$ Higenbottam T, Shipley MJ, Rose G. Cigarettes, lung cancer, and coronary heart disease: the effects of inhalation and tar yield. $J$ Epidemiol Community Health 1982; 36: 113-7.

Accepted for publication November 1988 